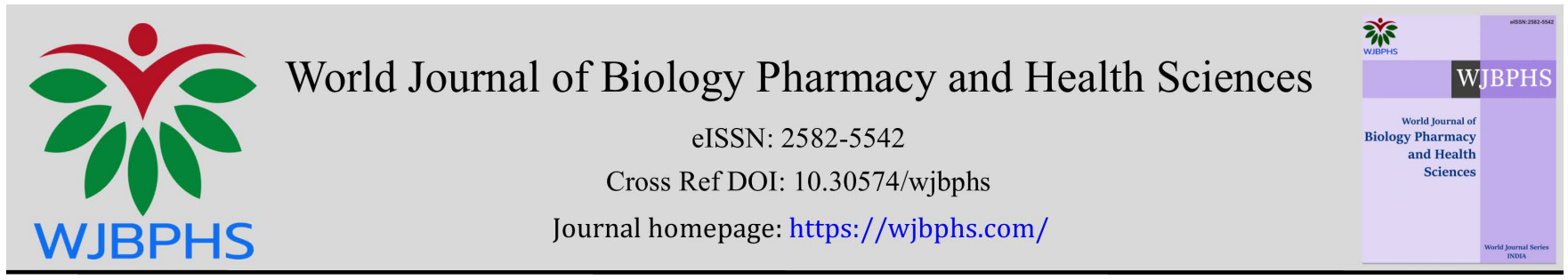

(CASE REPORT)

\title{
Kleptomania, a symptom of depression or frontotemporal dementia?
}

\author{
Cvjetković Bošnjak Miroslav Mina 1,2, Vejnović Tihomir Ana-Marija 1, 2, ", Živanović Vojislav Olga 1,2, Okanović \\ Slavko Milana 1,2, Pavlović Srđan Sanja 1,2 and Bjelan Siniša Sanja 1,2
}

${ }^{1}$ Department of Psychiatry and Psychological Medicine, Faculty of Medicine, University of Novi Sad, Serbia.

${ }^{2}$ Clinic of Psychiatry, Clinical Center of Vojvodina, Novi Sad, Serbia.

World Journal of Biology Pharmacy and Health Sciences, 2021, 06(02), 029-033

Publication history: Received on 19 February 2021; revised on 05 May 2021; accepted on 07 May 2021

Article DOI: https://doi.org/10.30574/wjbphs.2021.6.2.0029

\begin{abstract}
Three patients were presented in order to make differential diagnosis between affective disorder and dementia. All patients have diagnosis of affective disorder and they were in stable remission under antidepressive therapy. When pathological stealing occurred, there was a diagnostic dilemma: is it a new manifestation of affective disorder, rare side effect of serotonergic antidepressants or symptom of dementia. Neuroimaging methods, as well as neuropsychological testing identified that in these patients other symptoms of prefrontal dementia also existed. Frontotemporal dementia (FTD) is frequently misdiagnosed with depression, and so far, inadequately treated with higher doses of antidepressants. Such therapy could worsen clinical feature. These patients were successfully treated with combination of memantine and low doses of serotonergic antidepressants. In the future, multicentric investigation should be conducted to confirm effective therapeutic combination of psychopharmacs in cases of pathological stealing in FTD.
\end{abstract}

Keywords: Depressive disorder; Kleptomania; Dementia; Therapy possibilities

\section{Introduction}

Kleptomania implies an extra-strong need of stealing, preceded by an increase in tension by the act of theft itself and followed by feelings of excitement and satisfaction [1-4]. Essential feature of kleptomania is the lack of resistance to addictive behaviour/impulse. The motive for stealing is neither the money nor the use value of the item. After the action, feelings of satisfaction and guilt occur together with the desire to return the stolen item. Frequent repetition of this act does damage to the material, social and family environment. Kleptomania is classified as an impulse-control disorder in ICD-10 (International Classification of Diseases, 10 ${ }^{\text {th }}$ revision), under code F63.2 [5-7]. It can also be manifested along with symptoms of obsessive-compulsive spectrum, mood disorders, schizophrenia, and personality disorders and as a result of disinhibition in dementia [8-12]. The main problem with pathological stealing is the lack of treatment solutions. In this paper are presented three patients in remission of depressive disorder with symptom of pathological stealing. Therapy with memantine was successfully applied in combination with antidepressants.

\section{Case 1}

Patient is a 69-year-old female, retired and married. She was diagnosed with depressive disorder and she was treated for at least 30 years, with short periods without drugs. Her therapy was maprotiline with low dose of benzodiazepines. Patient was in remission for 7 years with this combination of drugs. The change in therapy was made two years ago, after she was diagnosed with Sjogren's syndrome as well. Therefore maprotiline was replaced by fluoxetine. After the change in therapy, the remission of depressive disorder persisted, but some new low-intensity symptoms occured. Few months ago the patient became sad and uninterested in social contact, she also started binge eating, with complains of

\footnotetext{
${ }^{*}$ Corresponding author: Vejnović Ana-Marija

Department of Psychiatry and Psychological, Faculty of Medicine, University of Novi Sad, Serbia.

Copyright (C) 2021 Author(s) retain the copyright of this article. This article is published under the terms of the Creative Commons Attribution Liscense 4.0.
} 
poor concentration and dysfunctionality in everyday activities - she could not make any plan of her activities. Symptoms of kleptomania also occured, which was quite odd for patient and her family. In last two months, she had repeatedly taken a piece of clothing, inappropriate in size and contrary to her style, from a hanger in a nearby boutique. She also stole a hand cream in a local market few times. During past few days the patient started to talk about suicidal ideas and the elaboration of a plan. She was admitted into hospital. The dose of fluoxetine had been reduced and discontinued. Due to sleep difficulties, mirtazapine was prescribed. During hospitalization patient complained of problems with concentration, forgetfulness, uncertainty in performing personal hygiene. There was a suspicion that dementia was developed. Computerized tomography (CT) scan of endocranium and neuroimaging were made and showed bilateral frontal osteoma, frontally calcified meningioma and frontal bone hyperostosis. Nevertheless, Positron Emission Tomography (PET)/CT findings indicate initial hypometabolisam in frontal lobes. Neuropsychological testing revealed frontal type dementia of moderate degree, with stereotypical responses, confabulations, memory impairment, executive dysfunctions and Mini-Mental State Exam (MMSE) score was 19. Due to clinical symptoms of dementia, memantine was prescribed as specific medication in gradually increased dose to $20 \mathrm{mg} /$ day. Evidently, after administration of memantine, pathological stealing had stopped. Patient's mood became adequate, she slept well and stopped overeating. Most of depressive symptoms disappeared, but lack of initiative persisted. Despite this, the patient had better functionality at home. During two-year period she regularly comes to check-up and there were no symptoms of worsening. There is clinical impression that medications successfully stopped the process of cognitive disorganization so far.

\section{Case 2}

Patient is a 69-year-old female, retired and married. She has diagnosis of recurrent depressive disorder for 15 years. She takes medication regularly and she has psychotherapy. For the last five years, patient was in remission on oral therapy with sertraline, mirtazapine and bromazepam. She has positive heredity for mental disorders. Her premorbid personality was rigid and hyper-scrupulous. She repeatedly attempted suicide in the past, while having depressive episodes. Some new clinical features appeared in recent months. For the last 3 months, almost every week she took money from dearest friends and family members during family meeting. Confronted with the behaviour, she stated that the reason for the theft was "to have more money", although she was well-situated. There were no auto-accusations after taking the money. She was admitted to the hospital for diagnostic purposes. CT scan performed diffusely reduced white brain density mostly pronounced para-ventricularly along the frontal and posterior horns of the lateral cerebral chambers. Neuropsychological testing indicated mild organic alteration, MMSE score was 22 with difficulties in concentration, executive dysfunction and confabulations. Patient also complained of irritability and crying without objective cause. In therapy, memantine was prescribed, gradually to daily dose of $20 \mathrm{mg}$. Over the coming weeks, the patient's condition became significantly better, she had more interest, affectively matched, and her sleep was well regulated. During her stay at the ward and at home, both her and her family members denied her urge to take money or other things. Patient was dismissed from the hospital. After outpatient PET/CT scan was made, findings suggest low glucose metabolism in the parietal lobes, left posterior cingulum, parietotemporal regions of the left brain, insula and temporal lobes. The clinical impression is that dementia occured in patient with depressive disorder, and therapy remains with memantine and low doses of sertraline $(25 \mathrm{mg} /$ day) and mirtazapine (15 mg/day). During following two years, the patient persists in well remission.

\section{Case 3}

Patient is a 67-year-old female, retired and married. She had diagnosis of bipolar affective disorder (BAP) and for almost 30 years she visited psychiatrists. Also, she was under medical treatment for hypothyroidism and hypertension. She has positive heredity for mental disorders. Her father was a potator. She had about ten episodes of depression in the past, and one hypomanic episode. For the last three years patient was in stable remission. She regularly takes prescribed therapy: sodium valproate $1500 \mathrm{mg} /$ day, clomipramine $50 \mathrm{mg} /$ day and clonazepam $1 \mathrm{mg} /$ day. Clinical picture changed in the last 6 months. Patient's husband noticed that she was sometimes confused, unable to do housework, she seemed scared, she did not remember important things and family events and periodically had pathological stealing behaviour. Patient was admitted to the hospital. CT scan (endocranial) followed by Magnetic Resonance Imaging (MRI) showed multi-infarcted lesions found subcortically mainly in the white mass of the frontal lobes. Neuropsychological testing indicates a moderately pronounced decline in cognitive potential as part of the development of dementia, most likely vascular etiology. PET/CT scan was not performed due to technical problems. The patient was treated with memantine, up to a dose of $20 \mathrm{mg} /$ day, continued with valproate and clonazepam and antidepressant was reduced to $25 \mathrm{mg} / \mathrm{day}$. The patient responded with affective compliance, but mild affective lability remaining in provocative situations. Pathological stealing behaviour disappeared. During the next two years, the patient persists in well remission. 


\section{Discussion}

In older age, the first symptom of frontotemporal dementia can manifest in form of behavioural changes, like pathological stealing. Diagnostic problem occurs if such patient has already been treated from depression or another mental disorder. When symptoms such as pathological stealing, loss of empathy, as well as problems with impulse control, affective turbulence, concentration etc. occur in patients in remission of depressive disorder, it is not clear if symptoms appear as a recidive of depressive disorder or as symptoms of another disorder, possibly dementia [13-18]. If pathological stealing occurs as a clinical sign the adequate therapy should be considered. According to literature, if this symptom is interpreted as a part of OCD spectrum (spectrum of conditions related to obsessive-compulsive disorder), it should be treated with higher doses of SSRIs (selective serotonin reuptake inhibitors) [19-22]. Differently, pathological stealing can appear as symptom of dementia, and treatment with SSRIs can worsen the clinical features. Dementia, particularly frontotemporal, is very often misdiagnosed and it is treated as depressive disorder. Either way, frontotemporal dementia represents a group of dementia with prevalence of 3-10\%. Symptoms usually occur between ages 45 and 65 [23-26]. Main symptoms of frontotemporal dementia are poor judgment, loss of empathy, inability to concentrate, personality and behavioural changes, impulsivity, language problems, overeating and loss of motivation.

In this case series, all patients were in remission of affective disorder. At first, when pathological stealing occured, there was diagnostic dilemma: is this impulse/behavioural problem symptom of affective disorder or side effect of serotonergic antidepressants or perhaps sign of dementia. After diagnostic procedures, it became evident that pathological stealing occured as behaviour due to brain dysfunction, especially frontal lobe. Diagnosis of frontotemporal dementia was assumed. Frontotemporal dementia (FTD), a common cause of dementia, is a group of disorders that occur when nerve cells in the frontal and temporal lobes of the brain are lost [21,27]. This causes the lobes to shrink. Some symptoms of FTD include dramatic personality changes and socially inappropriate, impulsive behaviour like pathological stealing $[13,28]$.

Pathological stealing represents an impulse-control disorder that can cause significant impairment and serious consequences. In described cases, initially there was a diagnostic problem, because patients had been treated due to depressive disorder. For family members, it was quite unexpectable when pathological stealing appeared. Diagnosis of frontotemporal dementia was made with sophisticated methods (neuroimaging methods and neuropsychological tests) in these patients. Memantine (3, 5-dimethyladamantan-1-amine) is a noncompetitive NMDA (N-methyl-D-aspartate) receptor antagonist with neuroprotective properties in cortical neurons. It was introduced in therapy of these patients, in combination with low doses of antidepressants, with satisfying results, so we presumed that such polypharmacy can be effective in some patients, with adequate monitoring due to polypragmasia.

In the future, multicentric research should be conducted to find out whether pathological stealing would respond to memantine in combination with SSRI, similar to results in described cases.

\section{Conclusion}

All presented patients were treated from depressive disorders for years, with typically signs and course. Unexpectedly, in hyper-responsible patients, pathological stealing appeared as a new symptom. Psychiatrists had their doubts, if this new symptom was part of depressive features, or perhaps sign of other mental disorder, like slowly progressive dementia. This suspicion was resolved with MRI and PET/CT, and adequate modification of therapy was successfully made. Due to therapy, symptoms of pathological stealing and following symptoms disappeared. Thereby, this case report could provide additional information for medical staff, especially for those who are starting practice, to acknowledge various mental disorders in already depressive older patients. Proper diagnosis and therapy should be applied on time in order to help patients with sign of depression and dementia.

\section{Compliance with ethical standards}

\section{Disclosure of conflict of interest}

The authors report no conflicts of interest in this work.

\section{Statement of informed consent}

Informed consent was obtained from all individual participants included in the study. 


\section{References}

[1] Goldman MJ. Kleptomania: making sense of the nonsensical. Am J Psychiatry. 1991; 148: 986-96.

[2] Eastman BD. A case of kleptomania. Am J Psychiatry. 1978; 35: 254-71.

[3] Aboujaoude E, Gamel N, Koran L. Overview of kleptomania and phenomenological description of 40 patients. J Clin Psychiatry. 2004; 6: 224-47.

[4] McElroy SL, Pope HG Jr, Hudson JI, Keck PE Jr, White KL. Kleptomania: a report of 20 cases. Am J Psychiatry. 1991; 148: 652-7.

[5] Talih FR. Kleptomania and potential exacerbating factors: a review and case report. Innov Clin Neurosci. 2011; 8(10):35-9.

[6] Kisa C, Yildirim SG, Goka C. Impusivity and mental disorders; Turk Psikiyatri Derg. 2005; 16: 46-54.

[7] Kim SW, Dysken MW, Pheley AM, Hoover KM. The Yale-Brown obsessive-compulsive scale: measure of internal consistency. Psychiatry Res. 1994; 51: 203-11.

[8] Grant JE, Levine L, Kim D, Potenza MN. Impulse control disorders in adult psychiatric inpatients. Am J Psychiatry. 2005; 162: 2184-8.

[9] Bayle FJ, Caci H, Millet B, Richa S, Olie J. Psychopathology and comorbidity of psychiatric disorders in patients with kleptomania. Am J Psychiatry 2003; 160: 1509-13.

[10] Merritt K, McGuire P, Egerton A. Relationship between glutamate dysfunction and symptoms and cognitive function in psychosis. Front Psychiatry. 2013; 4: 151.

[11] Hashimoto K, Malchow B, Falkai P, Schmitt A. Glutamate modulators as potential therapeutic drugs in schizophrenia and affective disorders. Eur Arch Psychiatry Clin Neurosci. 2013; 263: 367-77.

[12] Musazzi L, Treccani G, Mallei A, Popoli M. The action of antidepressants on the glutamate system: regulation of glutamate release and glutamate receptors. Biol Psychiatry. 2013; 73: 1180-8.

[13] Negar M, Charuworn K, Ashla M, Desarzovit R, Chavez D, Mendez M. Repetitive behaviors in frontotemporal dementia: compulsions or impulsions. J Neuropsyc Clin Neurosci. 2019; 31: 132-6.

[14] Birkhoff JM, Garberi CR. The behavioral variant of frontotemporal dementia: An analysis of the literature and a case report. Int J Law Psychiatry. 2016; 47: 157-63.

[15] Grant JE. Understanding and treating kleptomania: new models and new treatments. Isr J Psychiatry Relat Sci. 2006; 43: 81-7.

[16] Koran LM, Aboujaoude EN, Gamel NN. Escitalopram treatment of kleptomania: an open label trial followed by double blind discontinuation. J Clin Psychiatry. 2007; 68: 422-7.

[17] Viverberg EG, Schovs S, Musters PA, Verwijk E, Comis H, Koene T, et al. Cognitive deficits in patients with neuropsychiatric symptoms, a comparative study between behavioral variant between fronntotemporal dementia and primary psychiatric disorders. J Clin Psychiatry. 2017; 78: e.940-0946.

[18] Grant JE, Kim SW. An open-label study of naltrexone in the treatment of kleptomania. J Clin Psychiatry. 2002; 63: 349-56.

[19] Leombruni P, Lavagino L, Fassino S. Treatment of obese patients with binge eating disorder using topiramate: a review. Neuropsychiatr Dis Treat. 2009; 5: 285-392.

[20] Dannon PN. Topiramate for the treatment of kleptomania: a case series and review of the literature. Clin Neuropharmacol. 2003; 26: 1-4.

[21] Kindler S, Dannon PN, Iancu I, Sasson Y, Zohar J. Emergence of kleptomania during treatment for depression with serotonin selective reutake inhibitors. Clin Neuropharmacol. 1997; 20: 126-9.

[22] Demirkan AK, Iris Koc MS, Altintas M. Bipolar disorder and obsessive compulsive disorder comorbidity: a case report. Klin Psikofarmakol B. 2014; 24: 276.

[23] Gossink FT, Dois A, Krudop WA, Sikkers SA, Kerssenol S, Prins ND, et al. Formal psychiatric disorders are not overrepresented in behavioral variant frontotemporal dementia. J Alzheimer Dis. 2016; 51: 1249-56.

[24] Mendez MF, Chan AK, Shapiro JS, Miller P. Acquired sociopathy and frontotemporal dementia. Dementia Geriatr Cogn Disord. 2005; 20: 99-104. 
[25] Hai K, Enngoing Z, Libo J, Cinzia G, Venkatesh D, Suiit S et al. Pseudo-dementio: a neuropsychological review. Ann indian Acad Neurol. 2014; 17: 147-54.

[26] Mitchell JE, Burgard M, Faber R, Crosby RD, De Zwaan M. Cognitive behavioral therapy for compulsive buying disorder. Behav Res Ther. 2006; 44: 1859-65.

[27] Aizer A, Lowengrub K, Dannon PN. Kleptomania after head trauma: two case reports and combination treatment strategies. Clin Neuropharmacol. 2004; 27: 211-5.

[28] Mendez MF. Pathological stealing in dementia: poor response to SSRI medications. J Clin Psychiat. 2011; 72: 4189. 